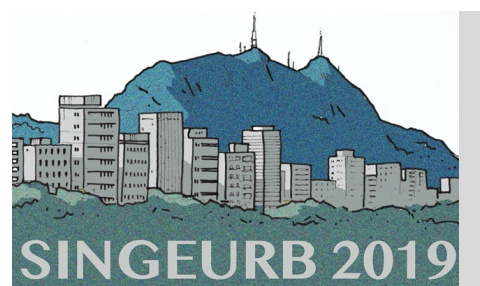

II Simpósio Nacional de Gestão e Engenharia Urbana

ABORDAGEM SISTÊMICA, ESCALAS E INTERSETORIALIDADE: DESAFIOS E POTENCIAIS DO DESENVOLVIMENTO URBANO SUSTENTÁVEL

\title{
O ícone arquitetônico como promoção urbana: o planejamento estratégico e a inserção do edifício cultural Cidade das Artes no Rio de Janeiro. ${ }^{1}$
}

\section{The architectural icon as urban promotion: strategic planning and the insertion of the cultural building City of Arts in Rio de Janeiro}

\author{
Pasquotto, Geise Brizotti ${ }^{1}$ \\ 1 USP, Travessa Jorge Norton, 45- Campinas-SP, geisebp@gmail.com
}

\begin{abstract}
RESUMO
O marketing urbano e o planejamento estratégico são utilizados onde a produção, consumo e lucro são os aspectos esperados como resultado das ações do poder público. A promoção urbana recria novas imagens para serem vendidas no mercado global, ao mesmo tempo em que promove rearranjos espaciais para readequá-las às novas necessidades locais. Diante deste aspecto, o Rio de Janeiro destacou-se como a cidade brasileira que mais utiliza da imagem e da promoção urbana em seu planejamento. Tais atitudes estratégicas de planejamento impactam na paisagem urbana e na morfologia da cidade.

O objetivo deste texto é compreender a questão da promoção urbana por meio de edifícios culturais na cidade do Rio de Janeiro adotando como exemplo a inserção da Cidade das Artes na Barra da Tijuca. Para tanto, utilizou-se dois aspectos para analisar a questão da promoção da paisagem urbana por meio de edifícios culturais: a) qual a "participação" do marketing urbano nas gestões políticas de 1995 a 2013, b) quais foram as estratégias de inserção dos edifícios icônicos culturais.
\end{abstract}

Palavras-chave: planejamento estratégico, edifício cultural, Rio de Janeiro.

\begin{abstract}
The urban marketing and strategic planning was used which the production, consumption and profit are expected aspects in result of the actions of public power. The urban promotion recreates new images to be sold in the global market, at the same time that promotes space re-arrangements to readjust them to new local necessities. Given this aspect, Rio de Janeiro stood out as the Brazilian city that most uses image and urban promotion in its planning. Such strategic planning attitudes impact the urban landscape and city morphology. The objective of this text is to understand the issue of urban promotion through cultural buildings in the city of Rio de Janeiro, adopting as an example the insertion of Cidade das Artes in Barra da Tijuca. To this end, two aspects were used to analyze the issue of promoting the urban landscape through cultural buildings: a) what is the "participation" of urban marketing in political management from 1995 to 2013 , b) what were the strategies for the insertion of Iconic cultural buildings.
\end{abstract}

Keywords: strategic planning, cultural building, Rio de Janeiro.

\footnotetext{
${ }^{1}$ PASQUOTTO, Geise Brizotti. O Ícone Arquitetônico como Promoção Urbana: o planejamento estratégico e a inserção do Edifício Cultural Cidade das Artes no Rio de Janeiro. In: II SIMPÓSIO NACIONAL DE GESTÃO E ENGENHARIA URBANA: SINGEURB, 2019, São Paulo. Anais... Porto Alegre: ANTAC, 2019.
} 


\section{INTRODUÇÃO}

Na década de 90 é implantado o planejamento estratégico no Rio de Janeiro, tornando-se a primeira cidade da América Latina a organizar um plano desta ordem. A decisão de alterar o enfoque de planejamento foi, principalmente, o resultado da evolução mundial: "uma vez que o capitalismo contemporâneo se globaliza, globalizam-se também as estratégias para administrá-lo de maneira eficiente" (MAGALHÃES, 1997).

Neste cenário de competição mundial, existem cinco ferramentas utilizadas pelo marketing urbano para o planejamento estratégico, sendo um deles o ícone arquitetônico (PASQUOTTO, 2011 ). Segundo Hazan (2003, online), os edifícios icônicos são construções que desde a sua concepção vem acarretar alguma expectativa em relação à sua implantação. A contratação de arquitetos conceituados mundialmente ajuda a "mitificar" as construções desde sua concepção. Esse processo de utilizar os arquitetos do star system internacional representam "uma cartada de peso na grande arena estratégica, a mídia" (CAMPOS \& SOMEKH, 2001).

A cultura, por sua vez, juntamente com a promoção urbana, tornou-se uma forte estratégia na supermodernidade/hipermodernidade (AUGÉ, 1994; LIPOVETSKY, 2004). Nas últimas décadas, como procura demonstrar Hall (2001, p.08), a economia "informacional" torna-se uma "economia cultural", que faz da cultura "uma mola propulsora" das novas exigências do mercado (ARANTES, 2007, p.152). Nesta metamorfose, a cultura se torna o grande negócio da cidade-mercadoria, e se torna cada vez mais espetacular.

Diante de tais questões, a metodologia utilizada para compreender a questão da promoção urbana por meio de edifícios culturais na cidade do Rio de Janeiro utilizou-se de dois aspectos. O primeiro é o entendimento de qual enfoque o marketing urbano foi inserido nas gestões políticas de 1995 a 2013, onde foi realizada uma análise das leis municipais sob este aspecto. Paralelamente, por meio de uma compilação jornalística e de análise dialética, identificou-se os argumentos críticos dos processos de inserção de edifícios icônicos (Figura 1). Esse direcionamento foi realizado seguindo a metodologia das ferramentas do marketing de PASQUOTTO (2011) aliadas às questões de "culturalização" (HÄUSSERMANN, 2000).

Figura 1 - Método de análise da promoção urbana por meio de edifícios culturais.

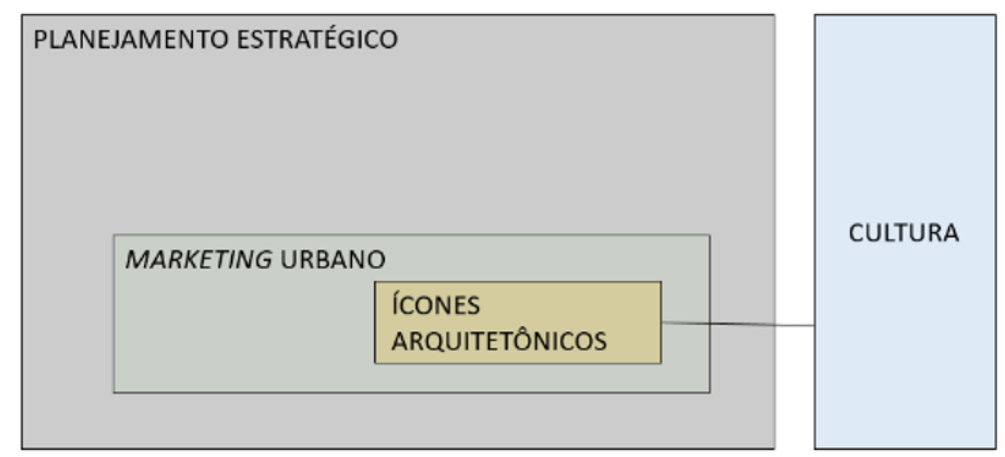

Fonte: Elaboração da autora, 2019.

\section{O PLANEJAMENTO ESTRATÉGICO E AS POLÍTICAS DE PROMOÇÃO URBANA DO RIO DE JANEIRO}

César Maia foi prefeito da cidade do Rio de Janeiro na gestão 1993-1996, 2001-2004 e 20052008 e o seu secretário de urbanismo Luiz Paulo Conde, no intervalo, de 1997-2000. Portanto, é possível contabilizar 16 anos de uma política orientada por ele.

No planejamento estratégico Rio Sempre Rio, política direcionada para o desenvolvimento local com a participação cidadã, foram contratados consultores catalães, em uma clara abordagem seguindo o "modelo de Barcelona". A implantação do plano levou a 
necessidade de criar estruturas de apoio, além de transformações administrativas dos atores da cidade (LOPES, 1996).

Este primeiro plano não buscou a elaboração de novas vocações, e sim, sua requalificação, ressaltando as vocações atuais. No entanto, na linha estratégica Rio 2004, o marketing urbano já aparece como ferramenta para o posicionamento internacional da cidade, antecipando as estratégias de inserção de ícones culturais do próximo plano. Segundo o plano (PCRJ, 1995, p. 30-31) o marketing urbano visa redefinir a imagem da cidade, criando um "produto Rio". É nesta discussão que surge a ideia ainda incipiente da inserção do museu Guggenheim no píer Mauá no porto da cidade, local central da cidade.

O segundo plano da gestão César Maia, intitulada As Cidades da Cidade objetivava enfatizar as relações de intercâmbio, negociação e colaboração, por meio dos diversos segmentos da sociedade, pelo princípio básico da participação cidadã (PCRJ, 2004, p. 18). Neste plano o marketing urbano continua, porém, com mais força. Na estratégia 1 ele é específico para a Barra da Tijuca, indicando ações para fortalecer o setor turístico e produzir um "produto Barra" (PCRJ, 2004, p. 64).

A partir de 2009, com a gestão do prefeito Eduardo Paes, foram elaborados mais dois PE's. $O$ primeiro plano prevê "pilares de aspirações": sociais, econômicas, ambientais e políticas. Nestes itens, é enfocado o desejo em voltar a ser um centro político e cultural, "tanto no cenário nacional quanto na cena internacional", remetendo novamente à promoção urbana por meio da divulgação mundial. Em abril de 2010 ocorre o lançamento do Plano de Promoção e Marketing da Cidade e em agosto, o Plano de Interação com o Turista que visava promover a requalificação urbana dos bairros da zona Norte e da área central da cidade e revitalizar a área portuária e bairros adjacentes.

No segundo Plano Estratégico (PE) da Prefeitura do Rio de Janeiro (2013-2016) o prefeito Eduardo Paes inicia o texto retomando os projetos de divulgação mundial iniciados em sua gestão passada, que os intitulou "conquistas", como os eventos internacionais e o projeto Porto Maravilha. E ele volta a mencionar a frase da edição passada reafirmando que o objetivo do plano é transformar o Rio de Janeiro na melhor cidade do Hemisfério Sul para se viver, trabalhar e conhecer, se tornando uma referência mundial em desenvolvimento sustentável e um dos principais centros políticos e culturais do cenário global.

\section{OS EDIFÍCIOS ÍCONES CULTURAIS DE PROMOÇÃO URBANA: Cidade das Artes na Barra da Tijuca.}

No primeiro PE de César Maia surge a ideia ainda incipiente da inserção do museu Guggenheim no píer Mauá no porto, local central da cidade. "A experiência internacional indicava que a recuperação da centralidade cultural exigia equipamentos de alta qualidade que cumprissem esse papel aglutinador" (MAIA, 2009, online).

No entanto, houve diversos percalços na sua inserção, devido ao valor do projeto, a escolha do arquiteto Jean Nouvel sem um concurso público, contratos questionáveis com a instituição Guggenheim, entre outros. Segundo o ex-prefeito, o museu foi cancelado por uma forte pressão de parte da imprensa, que estimulou a oposição política e culminou na obstrução do judiciário (MAIA, 2009, online)

Em fevereiro de 2012 o então secretário da Cultura, Ricardo Macieira e o embaixador, Raul Leite Ribeiro, foram pessoalmente encontrar com o arquiteto Christian de Portzmparc em seu escritório em Paris para convidá-lo a elaborar um projeto de sala de concertos no Museu de Arte Moderna do Rio de Janeiro. A resposta de Christian foi "que havia bons arquitetos brasileiros que fariam muito bem uma adaptação, respeitando integralmente o projeto de Reidy" (PORTZAMPARC, 2008, p. 33). Neste momento ficou claro: o arquiteto do star system queria projetar algo de equivalente importância ao seu nome e Maia tinha como ideal de governo fazer algo com grande "valor simbólico", onde o anexo não se encaixaria em nenhuma das duas premissas. 
O píer Mauá estava nos trâmites para o museu Guggenheim, portanto, era preciso refletir sobre outra opção de local. No programa de governo do então prefeito César Maia existia uma preocupação com a expansão da Barra e com a existência de "um comércio de entretenimento que só facilitava o faturamento sem uma programação de qualidade" (PORTZAMPARC, 2008, p. 21). Desta forma, a inserção de um edifício icônico cultural no local viria a ser o casamento perfeito entre as aspirações dos dois lados.

Desta forma, a ideia do museu Guggenheim foi substituída pela Cidade da Música/Artes. O local e o tema se modificam, mas a ideia de divulgação mundial por meio de edifícios ícones com arquitetos do star system prevalece (PASQUOTTO, 2016).

Alguns meses depois o arquiteto recebeu uma carta onde perguntavam se ele era bom arquiteto para salas de concertos. Ele, indignado com a pergunta, respondeu que naquele momento "era um dos melhores do mundo" (PORTZAMPARC, 2008, p. 33). "Essa foi a resposta que forneceu a base para que a prefeitura pudesse contratar o projeto através de dispensa de licitação, o que viria a gerar questionamentos em diversas esferas - inclusive na CPI conduzida para apurar o caso da Cidade da Música/Artes" (CAMARGO, 2011, p. 125). A partir desta manobra legal, não foi necessária a abertura de um concurso, impossibilitando qualquer chance de participação de arquitetos brasileiros ou estrangeiros na discussão do projeto.

A obra seguiu com diversas paralisações devido aos gastos. O edifício é uma das obras mais polêmicas de César Maia (Figura 2), consumindo apenas em 2008 um quarto dos investimentos da cidade, sendo assim alvo para a oposição (NOGUEIRA, 2008, online). Em 2018 foram abertas CPI's para investigar os gastos da obra e no mesmo ano estavam ocorrendo disputas para as eleições municipais (gestão 2009-2012) e o edifício foi considerado um "elefante branco" por quase todos os candidatos.

Figura 2 - Linha do tempo Gestão César Maia - Cidade da Música/Artes.

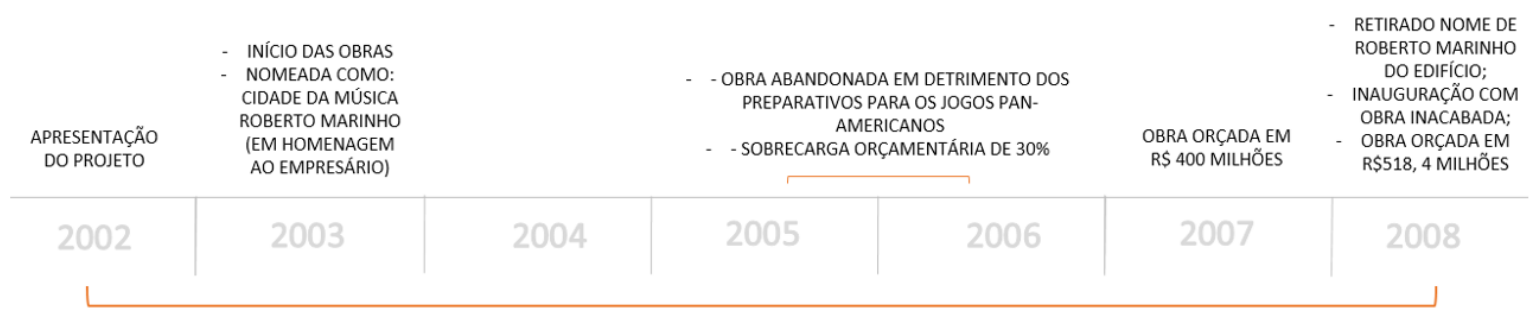

GESTÃO CÉSAR MAIA

Fonte: Elaboração da autora, 2015.

Na posse do prefeito Eduardo Paes, foi publicado no Diário Oficial do Município um decreto que suspendia a execução dos contratos e pagamentos e instaurava uma auditoria das obras de construção da Cidade da Música/Artes. Em novembro de 2013, Cesar Maia foi condenado por improbidade administrativa pela $3^{a}$ Vara de Fazenda Pública do Tribunal de Justiça. Em setembro de 2014 uma liminar no STJ suspendeu a decisão do Judiciário fluminense.

Pode ser resumido o período de concepção e execução da Cidade da Música/Artes na gestão César Maia em três etapas. A primeira de 2002 a 2004, consiste na concepção projetual, início das obras e orçamento nebuloso. Na segunda etapa de 2005 e 2006, período que antecedeu os Jogos Pan-Americanos, a obra ficou praticamente parada, gerando sobre custos e impaciência dos envolvidos. Na terceira etapa, na tentativa de finalização, houve problemas de aprovação e inauguração com a obra inacabada. A gestão de Eduardo Paes pode ser definida em dois períodos. O primeiro foi a tentativa de regularizar as contas e indiciar os suspeitos de algum tipo de fraude e, num segundo momento, terminar as obras que faltavam no complexo e re-inaugurá-lo para o público (Figura 3). 
Figura 3 - Linha do tempo da construção da Cidade das Artes e as respectivas gestões políticas.

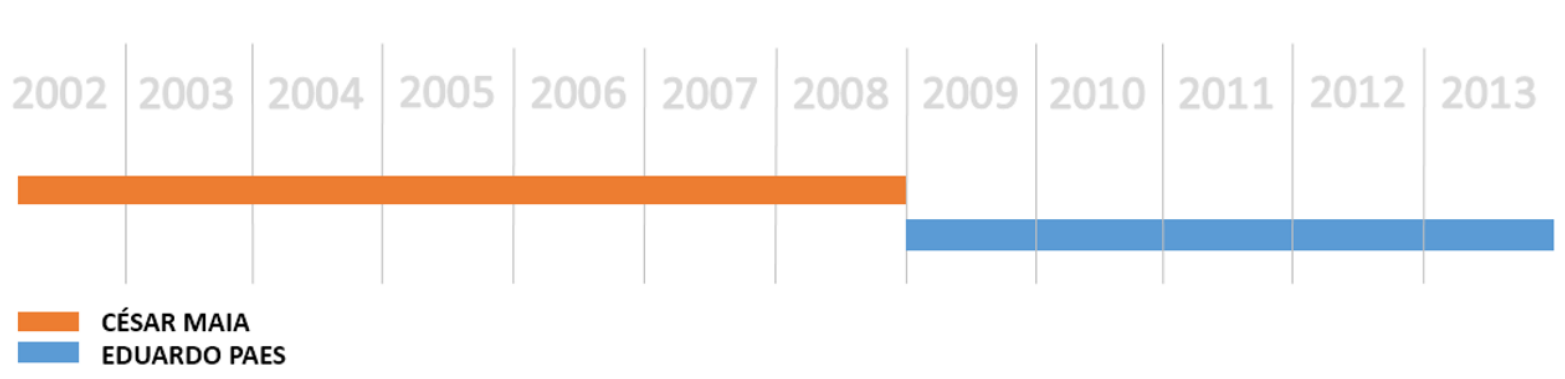

Fonte: Elaboração da autora, 2015.

Em 2009/2010, juntamente com as obras da Cidade das Artes, inicia-se também a operação urbana Porto Maravilha. Foi um projeto de requalificação urbana, com inserção de edifícios culturais icônicos. A questão principal, segundo Pires (2010, online), era o valor orçamentário desproporcional para as metas do plano, pois os investimentos destinados aos Projetos do Porto e Bairro Maravilha, TransOeste e Túnel da Grota Funda representavam quase $85 \%$ de todos os investimentos previsto no PE. Desta forma, Carlos Vainer (2009, p.04) afirma: "Sabemos desde já quem serão os ganhadores - as grandes empreiteiras, os grandes proprietários de terras da Barra da Tijuca, que terão seu patrimônio fundiário valorizado pelos investimentos bilionários".

Desta forma, em 2015, é inaugurado o Museu do Amanhã no Píer Mauá, realizado também por outro arquiteto internacional do star system, Santiago Calatrava, com o custo total de 230 milhões de reais.

\section{CONSIDERAÇÕES FINAIS}

Embora os planos de 1995 a 2013 tenham sido implementados por gestões diferentes, foi possível identificar uma orientação política de promoção urbana semelhante. A questão da inserção de ícones culturais realizados por arquitetos do star system estava inserida em todos os planos estratégicos como uma forma de adequação ao mercado mundial.

Tanto a área portuária onde está localizado o píer Mauá quanto a Barra da Tijuca, são locais estratégicos e interessantes principalmente para a promoção urbana e para o investimento imobiliário. Portanto, não é coincidência que tanto os ícones arquitetônicos analisados neste artigo, como os eventos internacionais (Olimpíadas), tenham utilizado as mesmas áreas de atuação.

\section{REFERÊNCIAS}

ARANTES, Otília Beatriz Fiori. Uma estratégia fatal: a cultura nas novas gestões urbanas. In: ARANTES, O.; VAINER, C.; MARICATO, E. A cidade do pensamento único: desmanchando consensos. 4.ed. Petrópolis: Vozes, 2007. p.14-16.

AUGÉ, Marc. Não-lugares: introdução a uma antropologia da supermodernidade. Campinas: Papirus, 1994.

CAMPOS, C. M.; SOMEKH, N. Desenvolvimento Local e Projetos Urbanos. In: Encontro Nacional da ANPUR, 9., 2001, Rio de Janeiro. Anais do IX Encontro Nacional da ANPUR, Rio de Janeiro, 2001.

HALL, Peter. Cities in civilization. New York: Fromm International, 2001.

HÄUSSERMANN, H; Grosstadt. Soziologische Stichworte. Opladen, Leske + Budrich, 2000. 
HAZAN, Vera Magiano. O papel dos ícones da contemporaneidade na revitalização dos grandes centros urbanos. Vitruvius - Periódico Mensal de Arquitetura, out. 2003, Arquitextos 041. Disponível em: <http://www.vitruvius.com.br/arquitextos/arq041/arq041_02.asp>. Acesso em: 01 jun. 2007.

LIPOVETSKY, Gilles. Os tempos hipermodernos. São Paulo: Barcarolla, 2004.

MAIA, César. César Maia Comenta Fatos que Atingiram a Centralidade Cultural do Rio. Rio de Janeiro, 2009. Disponível em http://www.cesarmaia.com.br/2009/05/teste259/ Acesso em: 12 mai 2013

NOGUEIRA, Italo. Família pede que Cidade da Música não tenha o nome de Roberto Marinho. Folha de São Paulo, Rio de Janeiro, 13 dez. 2008, Caderno Cotidiano. Disponível em: <http://wwwl.folha.vol.com.br/cotidiano/2008/12/478948-familia-pede-que-cidade-damusica-nao-tenha-o-nome-de-roberto-marinho.shtml>. Acesso em: 23 set. 2012.

PECRJ. Plano Estratégico da Cidade do Rio de Janeiro. Rio de Janeiro, 1995.

PECRJ. Plano Estratégico da Cidade do Rio de Janeiro. Rio de Janeiro, 2004.]

PASQUOTTO, Geise B. Edifícios Culturais e a Reabilitação de Áreas Centrais: o Complexo Cultural Teatro da Dança de São Paulo. Dissertação de Mestrado: Unicamp, 2011.

PORTZAMPARC, Christian. Uma Cidade da Música: um projeto de Christian de Portzamparc. Rio de Janeiro: Arte Ensaio, 2008.

VAINER, Carlos. Rio 2016: um jogo (Olímpico?) de cartas marcadas. Jornal dos Economistas. Rio de Janeiro, 2009, n. 245. Disponível em: <http://www.coreconrj.org.br/pdf/JE_dezembro2009.pdf>. Acesso em: 24 set. 2010. 